\title{
Engineering Herbicide-Tolerance Rice Expressing an Acetohydroxyacid Synthase with a Single Amino Acid Deletion
}

\author{
Jun Fang ${ }^{1, *,+} \mathbb{D}$, Changzhao Wan ${ }^{1,+}$, Wei Wang ${ }^{2}$, Liuyin Ma ${ }^{3} \mathbb{C}$, Xinqi Wang ${ }^{1}$, Can Cheng ${ }^{1}$, \\ Jihua Zhou ${ }^{1}$, Yongjin Qiao ${ }^{1}$ and Xiao Wang ${ }^{1}$ \\ 1 Crop Breeding and Cultivating Institute, Shanghai Academy of Agricultural Sciences, 1000 Jingqi Rd, \\ Shanghai 201403, China; wanchangzhao@163.com (C.W.); zw10@saas.sh.cn (X.W.); \\ chengcan222@126.com (C.C.); zhoujihua@saas.sh.cn (J.Z.); nkseed2010@aliyun.com (Y.Q.); \\ wangxiao.0127@163.com (X.W.) \\ 2 Shanghai Institute for Advanced Immunochemical Studies, ShanghaiTech University, 99 Haike Rd, Shanghai \\ 201210, China; kimi-ww@126.com \\ 3 Basic Forestry and Proteomics Research Center, Haixia Institute of Science and Technology, Fujian \\ Agriculture and Forestry University, Fuzhou 350002, China; lma223@fafu.edu.cn \\ * Correspondence: fangjunzju@163.com \\ + Those authors contributed equally to this work.
}

Received: 23 January 2020; Accepted: 12 February 2020; Published: 13 February 2020 updates

\begin{abstract}
The acetohydroxyacid synthase (AHAS) is an essential enzyme involved in branched amino acids. Several herbicides wither weeds via inhibiting AHAS activity, and the AHAS mutants show tolerance to these herbicides. However, most AHAS mutations are residue substitutions but not residue deletion. Here, residue deletion was used to engineering the AHAS gene and herbicide-tolerant rice. Molecular docking analysis predicted that the W548 of the AHAS was a residue deletion to generate herbicide tolerance. The AHAS- $\triangle \mathrm{W} 548$ protein was generated in vitro to remove the W548 residue. Interestingly, the deletion led to the tetramer dissociation of the AHAS, while this dissociation did not reduce the activity of the AHAS. Moreover, the W548 deletion contributed to multi-family herbicides tolerance. Specially, it conferred more tolerance to sulfometuron-methyl and bispyribac-sodium than the W548L substitution. Further analysis revealed that AHAS- $\Delta$ W548 had the best performance on the sulfometuron-methyl tolerance compared to the wild-type control. Over-expression of the $A H A S-\triangle W 548$ gene into rice led to the tolerance of multiple herbicides in the transgenic line. The T-DNA insertion and the herbicide treatment did not affect the agronomic traits and yields, while more branched-chain amino acids were detected in transgenic rice seeds. Residue deletion of W548 in the AHAS could be a useful strategy for engineering herbicide tolerant rice. The increase of branched-chain amino acids might improve the umami tastes of the rice.
\end{abstract}

Keywords: AHAS activity; the W548 deletion; multi-herbicide tolerance; rice

\section{Introduction}

Herbicide tolerance is an important trait of biotech crops worldwide [1]. Over the past 20 years, the strategy combining herbicide-tolerant (HT) crops with specific herbicides has made a significant contribution to weed control [2,3]. This system is reliable and desired by the market [4]. In the paddy, this strategy was the only economic and effective method to control weedy rice. Weedy rice has similar taxonomic and physiological features with rice. Some weedy rice is de-domesticated from commercial rice [5]. Since rice transplanting cultivation was shifted to direct sowing in Asia [6], weedy rice has become an important problem [7]. Penoxsulam, cyhalofop-butyl and pretilachlor are the most 
used herbicides in paddy [8]. Penoxsulam inhibits acetohydroxyacid synthase (AHAS, EC2.2.1.6, also known as acetolactate synthase). It eliminates weeds but not rice because rice Cytochrome $\mathrm{P} 450$ oxidase catalyzes O-dealkylation to 5-OH-penoxsulam and leads to herbicide degradation [9]. Cyhalofop-butyl is an inhibitor of acetyl coenzyme-A carboxylase (ACCase) but it can be metabolized and oxidized to form nontoxic diacid in rice [10]. Pretilachlor inhibits germination of plants including rice, and it is only used as a pre-planting or post-emergence application [11]. However, those herbicides are specialized for rice and are detoxified in rice. They are not effective for weedy rice [2]. The HT rice is engineered to tolerate the herbicides which could kill non-biotech rice cultivars. Imidazolinone-tolerant rice displays a promised strategy to control weedy rice in paddy fields [12]. Besides imidazolinone (IMI), other herbicide families, such as sulfonylurea (SU) and pyrimidinyl-benzoate (PYB), are popular in global agriculture [13]. The target of those herbicides is AHAS. Those herbicides control the grass and broadleaf weeds including weedy rice and are ideal candidates for the development of HT rice [2].

The AHAS mutants have been used to develop herbicide-tolerant crops. The AHAS is the first enzyme in the biosynthesis of three branched-chain amino acids (BCAA): valine, leucine, and isoleucine [14]. This enzyme is essential in plants and microorganisms but is absent in animals. Thus, the AHAS-inhibiting herbicides are non-toxin to animals. The herbicides bind to AHAS, inhibit catalytic efficiency and decrease BCAA contents [15]. This process retards plant growth or kills plants [16]. However, a weed evolves tolerance to SU due to a proline to histidine mutation in AHAS $[17,18]$. The mutation reduces the binding affinity between AHAS and SU, which produced herbicide tolerance. Learning from nature, scientists introduce various ahas mutants to develop HT crops [19]. Induced mutagenesis has been used to develop tolerant crops since 1992 [12]. The different mutations generate SU, IMI, or PYB tolerance in maize, sunflower, rice, wheat, and oilseed rape. However, the IMI-tolerant rice has been applied for 18 years, the weedy rice evolves IMI tolerance in Italy [20]. Novel HT rice is needed to deal with this problem.

The HT rice was engineered to tolerate multi-family herbicides through a residue deletion in the AHAS. The deletion was uncommon mutations because it led to protein degradation in certain cases [21]. Previous mutations in AHAS were substitution but not deletion [16]. The W548 residue (in this study, the amino acid numbering is based on rice AHAS) was an important site to generate herbicide tolerance in AHAS [14]. Its substitutions had been reported in many organisms, such as plants, bacteria, and yeasts. But it was unclear whether the W548 deletion led to herbicide tolerance in AHAS. Molecular docking is a method to predict the orientation and location of a small compound in a protein [22]. An algorithm was conducted to evaluate a series of compound-protein complexes to obtain the one with minimum energy. The complex could display the surface of the binding site and the conformation of the compound. We docked several herbicides in rice AHAS to study the interactions between the W548 and those herbicides. The W548 was removed in rice AHAS, then this modified enzyme (AHAS- $\Delta$ W548) were characterized in vitro. Transgenic rice was developed to evaluate the effects of ahas- $\Delta W 548$ gene on plant traits.

\section{Results}

\subsection{Herbicide Tolerance Predicted in AHAS Models}

Stereo models of the wild-type AHAS (AHAS-WT, NCBI, GenBank ID: BAB20812) were built with SU, IMI, and PYB herbicides. The SU family included four herbicides: sulfometuron-methyl (SM), rimsulfuron (RS), chlorimuron-methyl (CM), and flucarbazone-sodium (FC). The PYB and IMI families included bispyribac-sodium (BS) and imazethapyr (IT), respectively. In the AHAS-WT, the indole ring in the W548 faced with the triazine (FC) or the pyrimidine (SM, RS, CM, and BS) ring (Figure 1). Those face to face rings could form the $\pi-\pi$ interaction, which anchored the herbicides in the AHAS-WT. The W548 was far away from the IT which bound to the protein with S627 [23]. The herbicides blocked the channels which substrates passed into the catalytic centers in the AHAS-WT. After deleting the W548, the scores dropped more than $10 \%$ for five herbicides (Table 1). Due to a lack 
of homologous crystal structures of the AHAS- $\triangle$ W548, molecular docking could not produce precious structures. The scores implied that the W548 deletion might weaken the interaction and change the channel conformation. Although no interaction was found between the W548 and the IT, the W548 deletion opened the mouth of the channel. Those results supposed that the W548 deletion could lead to herbicide tolerance. To verify this prediction, the AHAS- $\triangle$ W548 was expressed and characterized in vitro to examine the effects of the deletion.
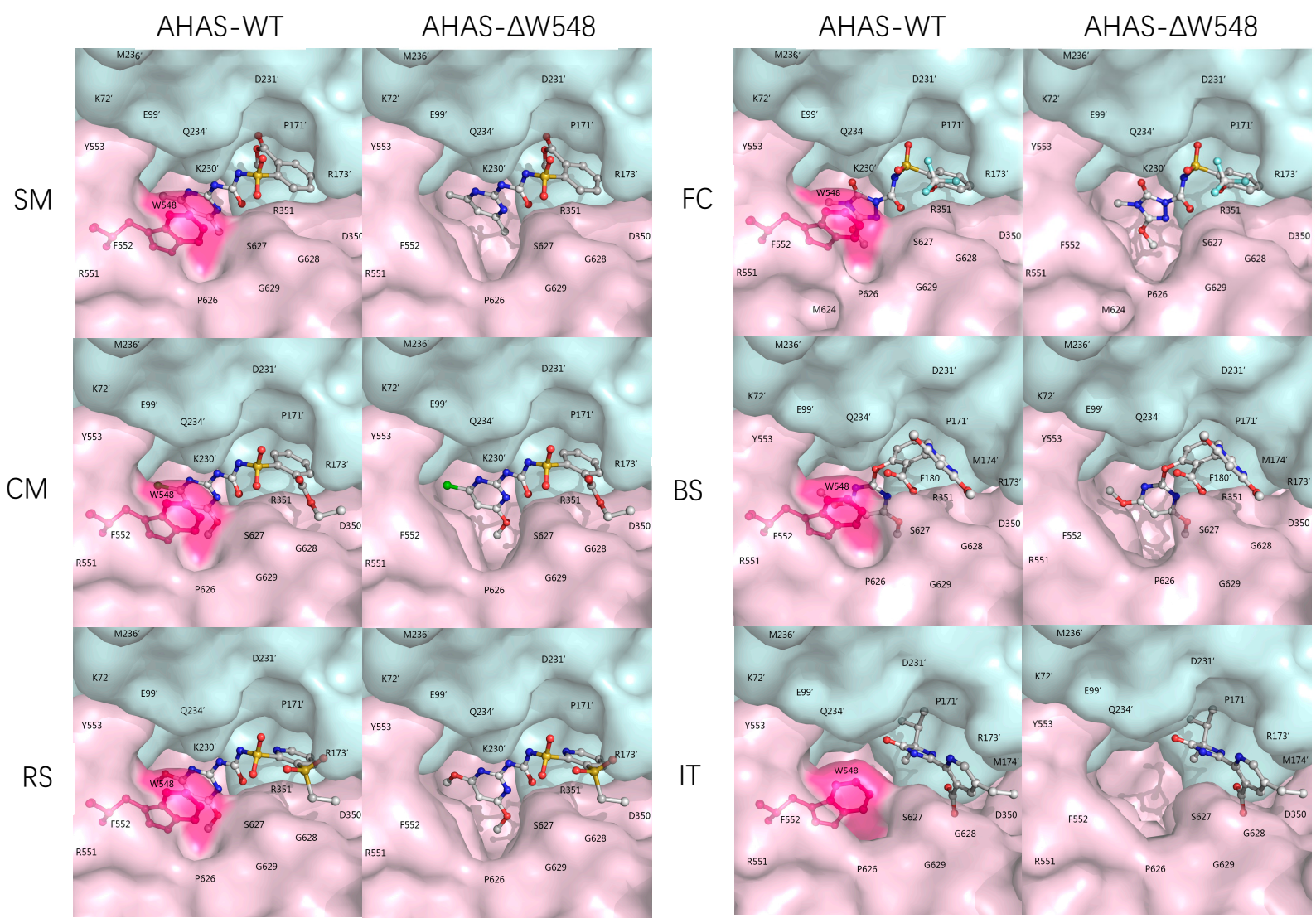

Figure 1. Herbicides bind and block the channel leading to the active site. The molecular surfaces of the monomers were depicted as pink and cyan, respectively. The residues were labeled on the surfaces. ' indicated residues from different monomers. W548 was shown as a red stick-ball model with the red surface. The herbicides were shown as color stick-ball models with white carbon atoms, blue nitrogen, red oxygen, cyan fluorine, yellow sulfur, and green chloride.

Table 1. Molecular docking scores for herbicides in different AHAS.

\begin{tabular}{ccc}
\hline Herbicides & AHAS-WT & AHAS- $\mathbf{W}$ 548 \\
\hline SM & 7.159 & 5.731 \\
RS & 7.491 & 5.834 \\
CM & 7.507 & 5.784 \\
FC & 7.681 & 6.619 \\
BS & 7.208 & 6.389 \\
IT & 7.641 & 7.544 \\
\hline
\end{tabular}

\subsection{The W548 Deletion Dissociate the Tetramer in Vitro}

The AHAS-GST and mature AHAS proteins in a gel showed high purity of proteins (Figure 2). The GST-AHAS and tag-free AHAS were observed at predicted molecular weights of $90 \mathrm{kDa}$ and $64 \mathrm{kDa}$, respectively. Gel filtration chromatography revealed clear peaks of expected molecular weight (Figure 3). No aggregation or degradation peaks were observed. Those results indicated that purified 
proteins were homogeneous and well folded. The AHAS-WT trace consisted of two peaks: one main dimer peak $(128 \mathrm{kDa})$ and one small tetramer peak $(256 \mathrm{kDa})$. Only one dimer peak was observed in the AHAS- $\Delta$ W548 trace. The tetrameric peak was not detected for the AHAS- $\Delta$ W548. This suggested that the residue deletion led to the dissociation of a tetramer into dimers.

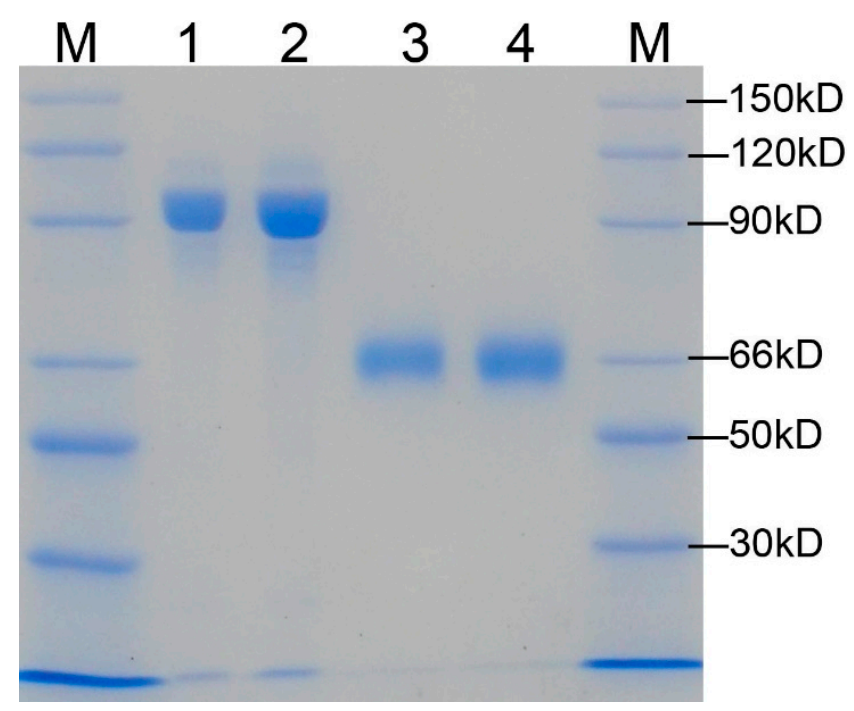

Figure 2. Gel image of SDS-PAGE for the purified AHAS. Lane 1: GST-AHAS-WT; Lane 2: GST-AHAS- $\triangle$ W548; Lane 3: mature AHAS-WT; Lane 4: mature AHAS- $\Delta$ W548. M: protein marker. The molecular weights of bands in the marker were indicated.

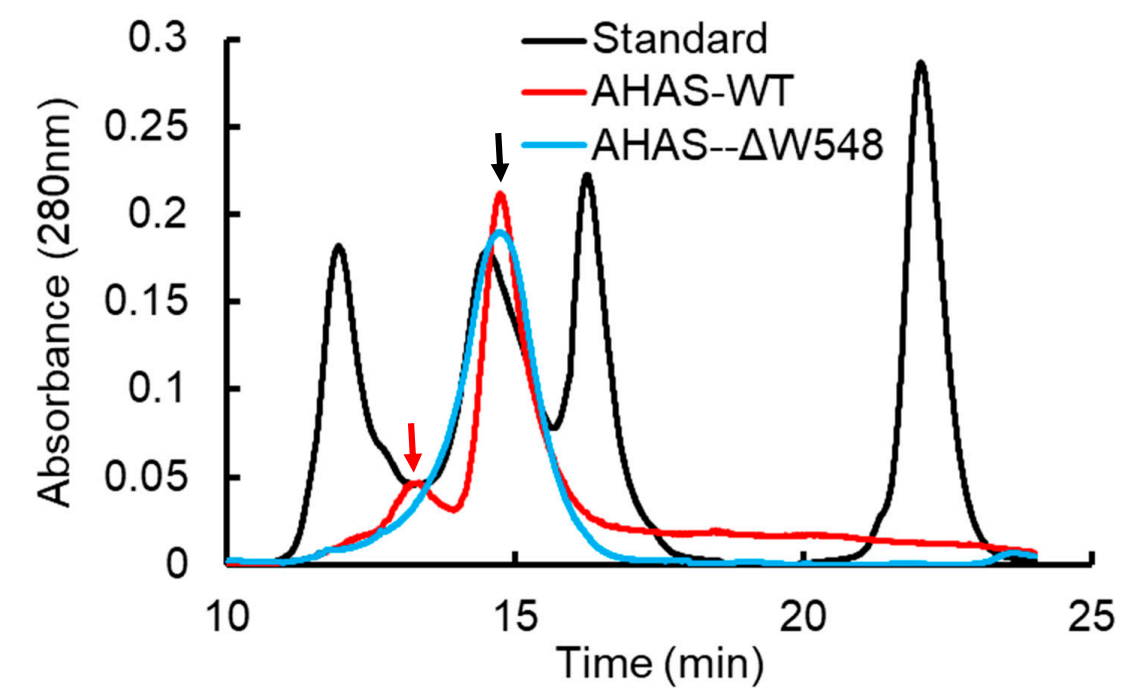

Figure 3. Gel filtration chromatography analysis of purified AHAS. AHAS-WT and AHAS- $\triangle$ W548 are shown as red and blue traces, respectively. The black trace is the molecular weight standard. From left to right, the molecular weights of the standards were $670,158,44$ and $1.35 \mathrm{kD}$. The dimer peak (128 $\mathrm{kDa})$ and tetramer peak $(256 \mathrm{kDa})$ are indicated separately by the black arrow and red arrow.

\subsection{Multi-Herbicide Tolerance of the AHAS- $\triangle W 548$}

The activity of the AHAS-WT decreased as herbicide concentration increased (Figure 4). Obviously, the AHAS- $\triangle$ W548 remained activities at maximum concentrations of herbicides. Especially, the mutated AHAS displayed high activities in the SU solutions. Moreover, the AHAS- $\Delta$ W548 conferred good tolerance to the PYB/IMI. Kinetic parameters showed no significant variation for the AHAS- $\triangle \mathrm{W} 548$ in the absence of an herbicide (Table 2). Similar results were observed in the presence of three SU herbicides (SM/RS/CM). The catalytic efficiency of the AHAS- $\triangle$ W548 was inhibited by FC, BS, and IT. 
The reaction velocity $\left(K_{\text {cat }}\right)$ of the AHAS- $\Delta$ W548 decreased significantly in the FC solution, suggesting that FC was bound and blocked the channel in the mutant. The BS or IT significantly inhibited the reaction velocity and binding affinity of the mutated protein. It implied that the BS or IT bound to the channel and affected the active site. Among all herbicides, SM inhibited the AHAS-WT at a low concentration, but did not affect the AHAS- $\triangle \mathrm{W} 548$ at a high concentration. Thus, SM was a good reagent to select the tissues expressing the ahas $-\Delta W 548$ gene.

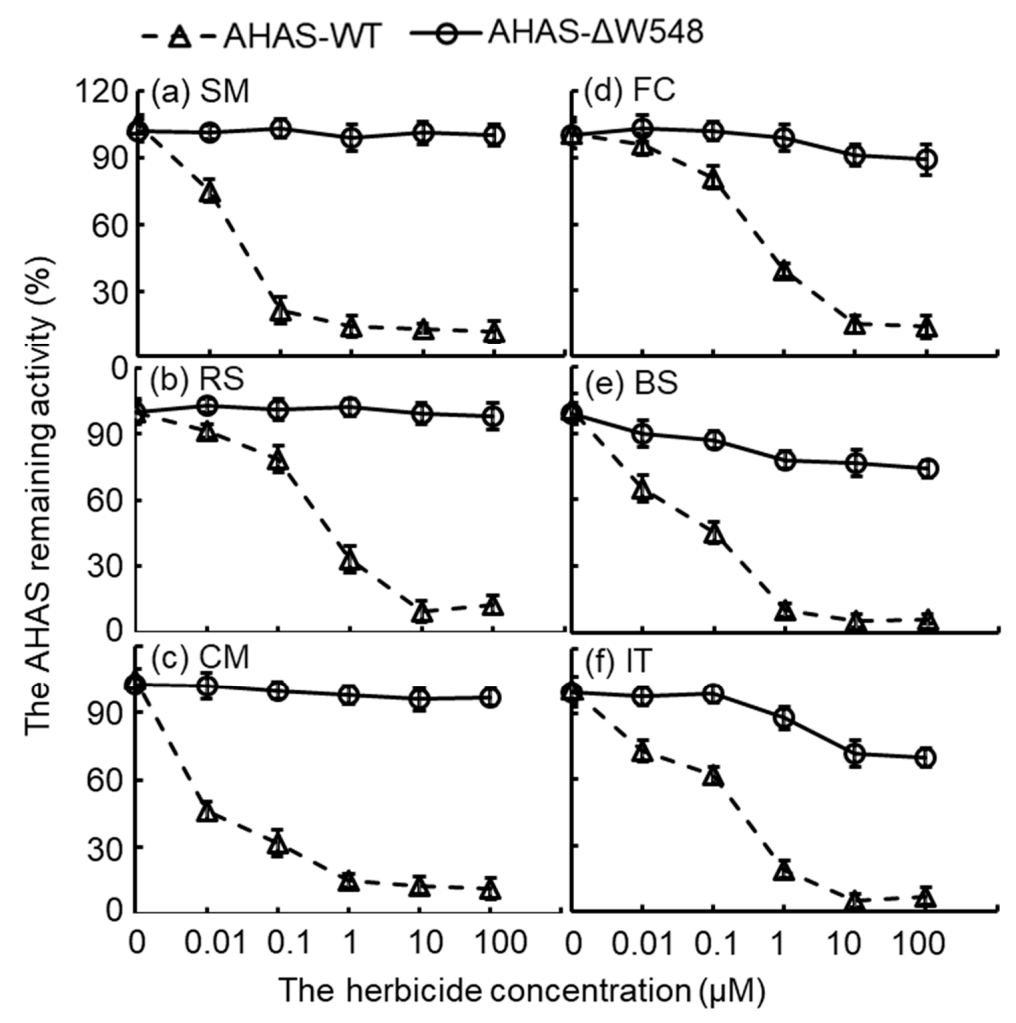

Figure 4. Bioassay curves of AHAS activities in the presence of six herbicides. AHAS-WT was inactive when an herbicide was more than $10 \mu \mathrm{M}$. AHAS- $\triangle \mathrm{W} 548$ remained active at high concentrations of herbicides. Panels of (a-f) displayed the AHAS remaining activities in solutions of different herbicides: (a) sulfometuron-methyl (SM), (b) rimsulfuron (RS), (c) chlorimuron-methyl (CM), (d) flucarbazone-sodium (FC), (e) bispyribac-sodium (BS), and (f) imazethapyr (IT). Error bars represented the errors from triplicate measurements. Triangles are AHAS-WT, and circles are AHAS- $\Delta$ W548.

Table 2. Kinetic parameters of the AHAS-WT and AHAS- $\Delta$ W548 enzymes.

\begin{tabular}{|c|c|c|c|}
\hline Enzyme/Herbicide ${ }^{a}$ & $K_{m}(\mathbf{m M})^{\mathbf{b}}$ & $K_{c a t}\left(\mathrm{~s}^{-1}\right)$ & $\begin{array}{l}\text { Catalytic Efficiency } \\
K_{c a t} / K_{m}\left(\mathrm{~S}^{-1} \mathrm{mM}^{-1}\right)\end{array}$ \\
\hline AHAS-WT & $9.2 \pm 0.4$ & $6.7 \pm 0.3$ & $0.71 \pm 0.03$ \\
\hline AHAS- $\Delta$ W548 & $9.4 \pm 0.4$ & $6.6 \pm 0.5$ & $0.70 \pm 0.05$ \\
\hline AHAS- $\Delta$ W548 (SM) & $9.3 \pm 0.6$ & $6.6 \pm 0.3$ & $0.72 \pm 0.05$ \\
\hline AHAS- $\Delta$ W548 (RS) & $9.4 \pm 0.5$ & $6.5 \pm 0.4$ & $0.69 \pm 0.04$ \\
\hline AHAS- $\Delta$ W548 (CM) & $9.2 \pm 0.3$ & $6.5 \pm 0.4$ & $0.71 \pm 0.03$ \\
\hline AHAS- $\Delta$ W548 (FC) & $9.4 \pm 0.3$ & $5.9 \pm 0.4^{*}$ & $0.63 \pm 0.03 *$ \\
\hline AHAS- $\Delta$ W548 (BS) & $11.3 \pm 0.6^{* *}$ & $5.8 \pm 0.3^{* *}$ & $0.51 \pm 0.04^{* *}$ \\
\hline AHAS- $\Delta$ W548 (IT) & $12.1 \pm 0.3^{* *}$ & $5.1 \pm 0.3^{* *}$ & $0.42 \pm 0.03 * *$ \\
\hline
\end{tabular}

Values are given as means ( \pm standard deviation). ${ }^{*}$ represented significantly different from AHAS-WT without an herbicide treatment at $p<0.05,{ }^{* *}$ represented significantly different from AHAS-WT without an herbicide treatment at $p<0.01$. a: The enzyme was measured in the absence or presence of an herbicide. An herbicide was indicated in a bracket. b: $K_{m}$ means the Michaelis-Menten constant. 


\subsection{Transgenic Rice with Herbicide Tolerance}

The T-DNA cassette expressing the ahas- $\Delta W 548$ gene (Figure 5) was combined with SM to select HT callus and shoots in tissue culture procedure. Twenty-one lines are positive in the T0 generation after the polymerase chain reaction (PCR) scan (Figure 6). The T1 plants from eighteen lines survived with the SM treatment. The levels of the ahas expression indicated that the ahas- $\Delta W 548$ gene was over expressed in those survived lines (Figure S1). Some lines displayed accepted agronomic traits (Table S1), but the Line9 was the best one for comprehensive traits. The T2 plants of Line9 did not display significantly difference with its parent Xiushui134 in field (Table 3). Moreover, the Line9 showed tolerance to multi-family herbicides (Figure 7). Relative heights were not affected by all SU herbicides (Figure 8). Line9 was dwarfed with the BS or IT treatment. The SM treatment had no effect on the agronomic traits of the Line9. Contents of total proteins in brown rice were similar between the Xiushui134 and the Line9 (Table 4). Contents of BCAA increased significantly in the Line9, while other free amino acids kept similar contents. The SM treatment did not change the BCAA contents in brown rice.

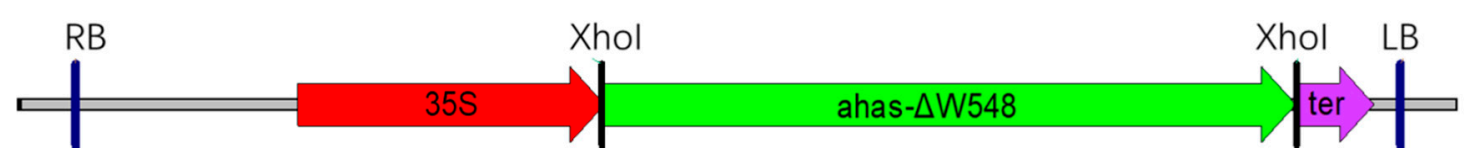

Figure 5. Diagram of T-DNA cassette for rice transformation. The ahas- $\Delta W 548$ gene replaced the hygromycin resistant gene and served as a selection marker. This gene was driven by a 35S promoter. RB and LB: right and left border of T-DNA; 35S: 35S promoter of the CaMV; ter: terminator of the CaMV.

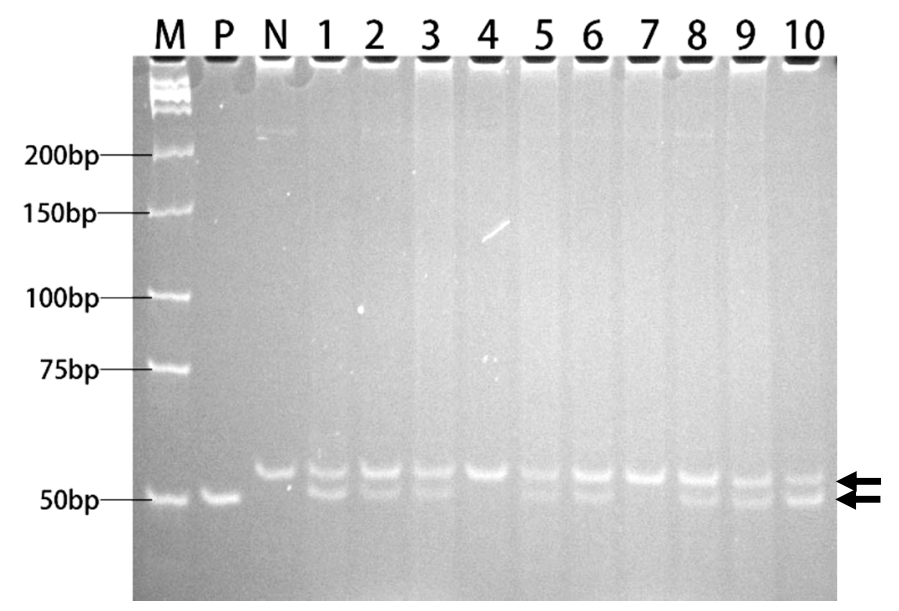

Figure 6. PAGE analysis of PCR products for ahas fragments. Lane 1-10: PCR products from Line 1-10 of transgenic rice. P: positive control (plasmid DNA of 1300-AHAS- $\Delta$ W548). N: negative control (genomic DNA of Xiushui134). M: Low MW DNA marker-A. The molecular weights were indicated. Two arrows showed two amplified fragments: upper arrows indicated wildtype ahas fragments, lower arrows indicated ahas- $\Delta W 548$ fragments. 
Table 3. Agronomic traits of the Xiushui134 and Line9 plants.

\begin{tabular}{|c|c|c|c|c|c|c|c|c|c|}
\hline Line Name & $\begin{array}{l}\text { Plant Height } \\
\text { (cm) }\end{array}$ & $\begin{array}{c}\text { Panicle } \\
\text { Numbers Per } \\
\text { Plant }\end{array}$ & $\begin{array}{c}\text { Length of } \\
\text { Panicle }(\mathrm{cm})\end{array}$ & $\begin{array}{c}\text { Grains Per } \\
\text { Panicle }\end{array}$ & $\begin{array}{l}\text { Seed-Setting } \\
\text { Rate }(\%)\end{array}$ & $\begin{array}{l}\text { 1000-Grain } \\
\text { Weight (g) }\end{array}$ & $\begin{array}{l}\text { Yield Per } \\
\text { Plant (g) }\end{array}$ & $\begin{array}{c}\text { Grain } \\
\text { Width }(\mathrm{cm})\end{array}$ & $\begin{array}{c}\text { Grain } \\
\text { Length }(\mathrm{cm})\end{array}$ \\
\hline Xiushui134 & $94.1 \pm 1.3$ & $8.6 \pm 0.4$ & $14.2 \pm 1.8$ & $151.2 \pm 9.6$ & $90.2 \pm 1.5$ & $26.9 \pm 0.7$ & $28.5 \pm 2.9$ & $3.3 \pm 0.2$ & $6.8 \pm 0.3$ \\
\hline Line9 & $92.2 \pm 2.1$ & $8.9 \pm 0.5$ & $14.8 \pm 1.6$ & $145.9 \pm 8.7$ & $91.5 \pm 1.3$ & $27.2 \pm 1.5$ & $29.8 \pm 3.6$ & $3.3 \pm 0.2$ & $6.9 \pm 0.5$ \\
\hline Line9 (SM) & $93.5 \pm 1.8$ & $8.5 \pm 0.5$ & $15.1 \pm 1.2$ & $153.5 \pm 10.8$ & $90.5 \pm 2.1$ & $26.3 \pm 1.3$ & $27.3 \pm 2.1$ & $3.3 \pm 0.2$ & $6.8 \pm 0.4$ \\
\hline
\end{tabular}




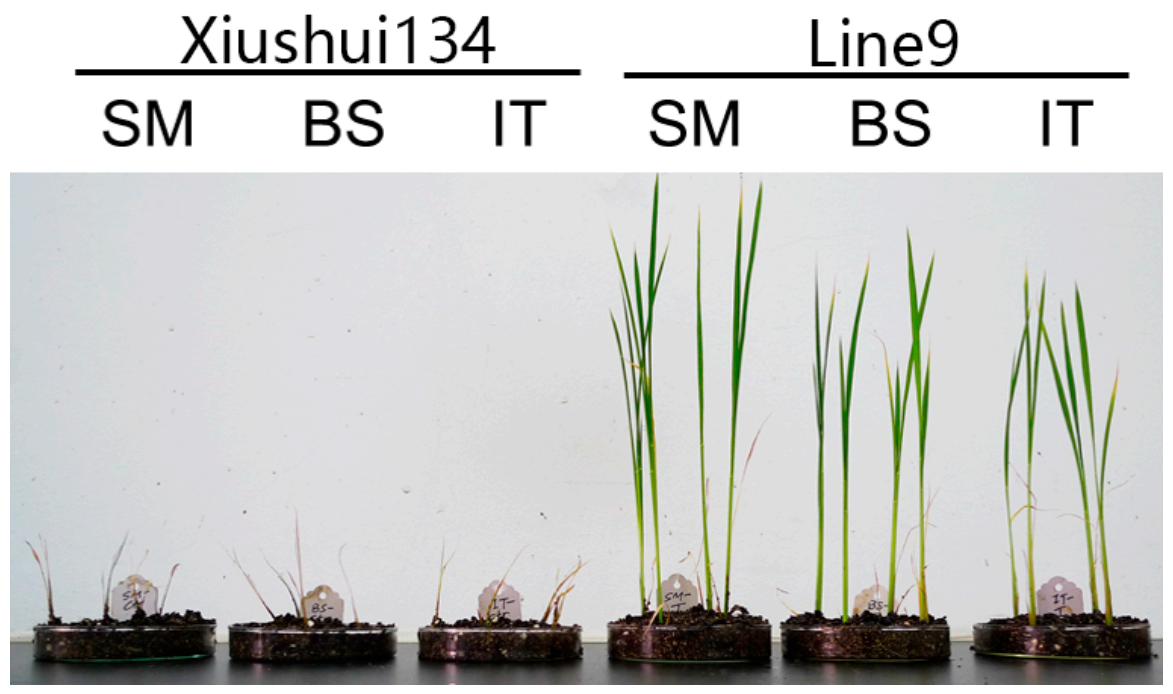

Figure 7. Image showing rice plants with herbicide treatment. The plants were treated with $0.25 \mathrm{~g} / \mathrm{L}$ $\mathrm{SM}, 0.8 \mathrm{~g} / \mathrm{L}$ BS or $2.2 \mathrm{~g} / \mathrm{L}$ IT at the seedling stage. After two weeks, the Xiushui134 plants withered, while the Line9 plants survived with the herbicide treatment.

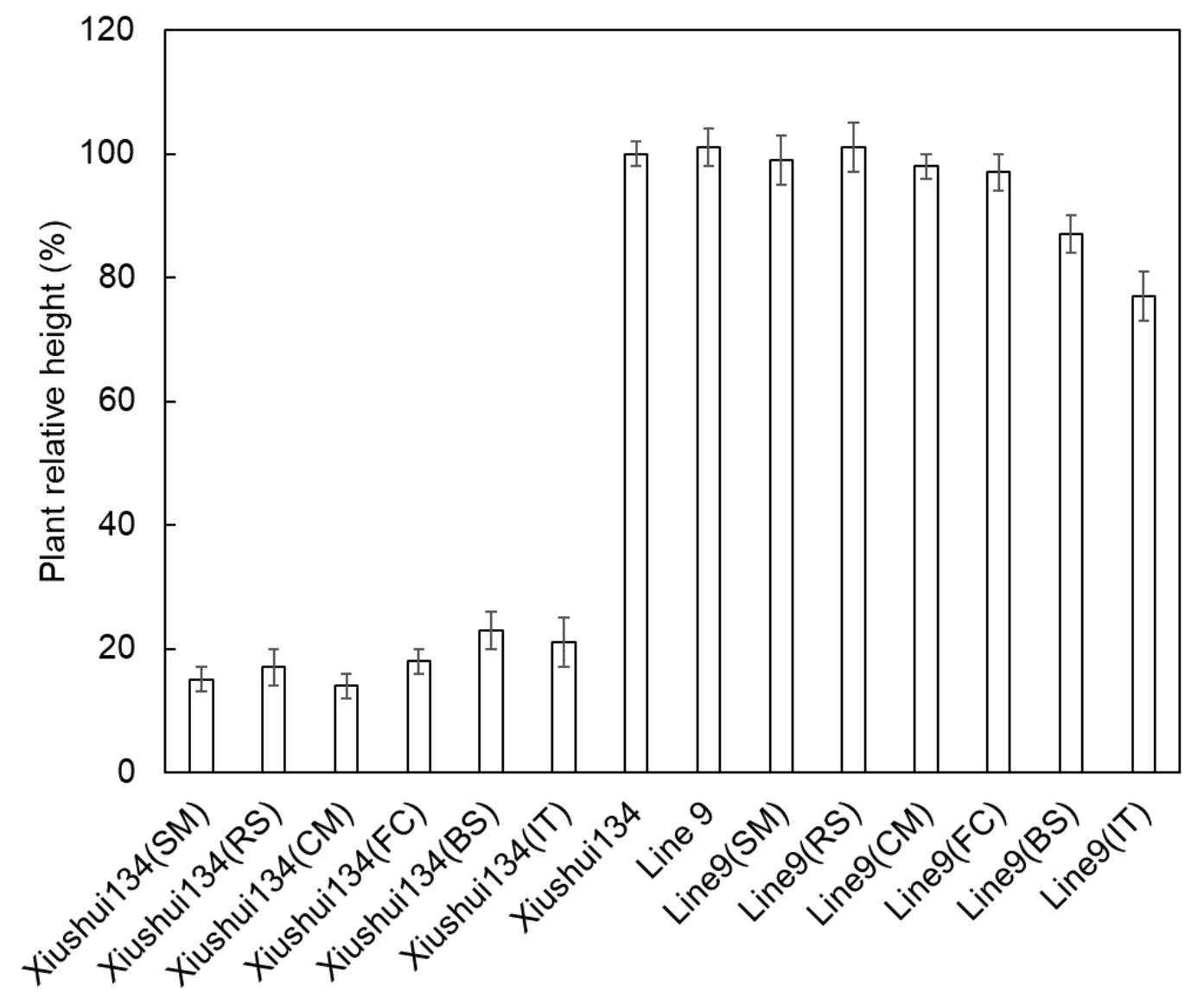

Figure 8. Plant relative height of Xiushui134 and Line9 at the seedling stage. The Xiushui134 plants were killed with herbicide treatments, and the relative heights were around $20 \%$. The Line9 plants grew well with SU herbicide treatments. The growth of Line9 was inhibited by a PYB (BS) and IMI (IT) herbicides. Error bars represent the errors from multiple measurements. 
Table 4. Total protein and free Amino Acids in the Xiushui134 and Line9 seeds.

\begin{tabular}{cccccccc}
\hline Compound & Xiushui134 & Line9 & Line9 (SM) & Compound & Xiushui134 & Line9 & Line9 (SM) \\
\hline Ile & $18 \pm 8$ & $79 \pm 26^{* *}$ & $75 \pm 23^{* *}$ & Trp & $89 \pm 29$ & $95 \pm 21$ & $85 \pm 31$ \\
Leu & $23 \pm 11$ & $82 \pm 25^{* *}$ & $87 \pm 29^{* *}$ & Gly & $103 \pm 20$ & $105 \pm 23$ & $99 \pm 31$ \\
Val & $51 \pm 17$ & $224 \pm 32^{* *}$ & $231 \pm 28^{* *}$ & Gln & $145 \pm 29$ & $167 \pm 35$ & $154 \pm 31$ \\
Phe & $22 \pm 9$ & $25 \pm 7$ & $29 \pm 6$ & Pro & $154 \pm 31$ & $176 \pm 30$ & $181 \pm 27$ \\
Lys & $35 \pm 11$ & $28 \pm 9$ & $31 \pm 12$ & Ala & $266 \pm 29$ & $311 \pm 35$ & $304 \pm 33$ \\
His & $38 \pm 16$ & $47 \pm 8$ & $46 \pm 9$ & Ser & $270 \pm 21$ & $302 \pm 29$ & $298 \pm 37$ \\
Thr & $42 \pm 9$ & $45 \pm 11$ & $49 \pm 13$ & Arg & $340 \pm 31$ & $362 \pm 49$ & $388 \pm 37$ \\
Met & $46 \pm 20$ & $51 \pm 12$ & $41 \pm 22$ & Asp & $513 \pm 46$ & $501 \pm 56$ & $481 \pm 43$ \\
His & $48 \pm 17$ & $41 \pm 21$ & $59 \pm 15$ & Asn & $759 \pm 57$ & $780 \pm 62$ & $776 \pm 69$ \\
Tyr & $75 \pm 36$ & $89 \pm 22$ & $95 \pm 32$ & Glu & $1527 \pm 246$ & $1382 \pm 321$ & $1659 \pm 356$ \\
Total Protein & $8.9 \pm 0.5$ & $9.1 \pm 0.7$ & $9.2 \pm 0.6$ & & & & \\
\hline
\end{tabular}

Values are given as means ( \pm standard deviation). The SM was applied to estimate the effects of an herbicide on the Line9. a: Unit of free amino acids was nM. b: Unit of total protein was $\%$. ${ }^{* *}$ represented significantly different from the Xiushui134 at $p<0.01$.

\section{Discussion}

\subsection{Effects of the W548 Deletion on Rice AHAS}

Tetramer dissociation was an unexpected feature of the AHAS- $\Delta$ W548. The S627 position was close to the W548 in the structure; they located distant from the tetramer interface (Figure 9). However, the S627N mutation did not lead to tetramer dissociation [23]. The W548 deletion was not predicted to break the interface. The W548 deletion might lead to structure rearrangement and indirectly disrupt the tetramer interface. Catalytic efficiency depended on the active site in a dimer [24]. The remained catalytic efficiency indicated that the AHAS- $\triangle$ W548 dimer contained an intact active site. The W548L mutant was used widely in HT crops [14]. When a herbicide's concentration was $100 \mu \mathrm{M}$, the W548L mutant remained about 20\% activity in the SM solution and less than $10 \%$ activity in the BS solution $[25,26]$. At this concentration, the AHAS- $\triangle$ W548 remained about $100 \%$ activity in the SM solution and more than $60 \%$ activity in the BS solution. It implied that the W548 deletion had more tolerance to SM and BS than the W548L substitution. The enhanced tolerance might be a result of the gap at the mouth of the AHAS- $\triangle$ W548 channel. Meanwhile, no gap happened in the W548L substitution.

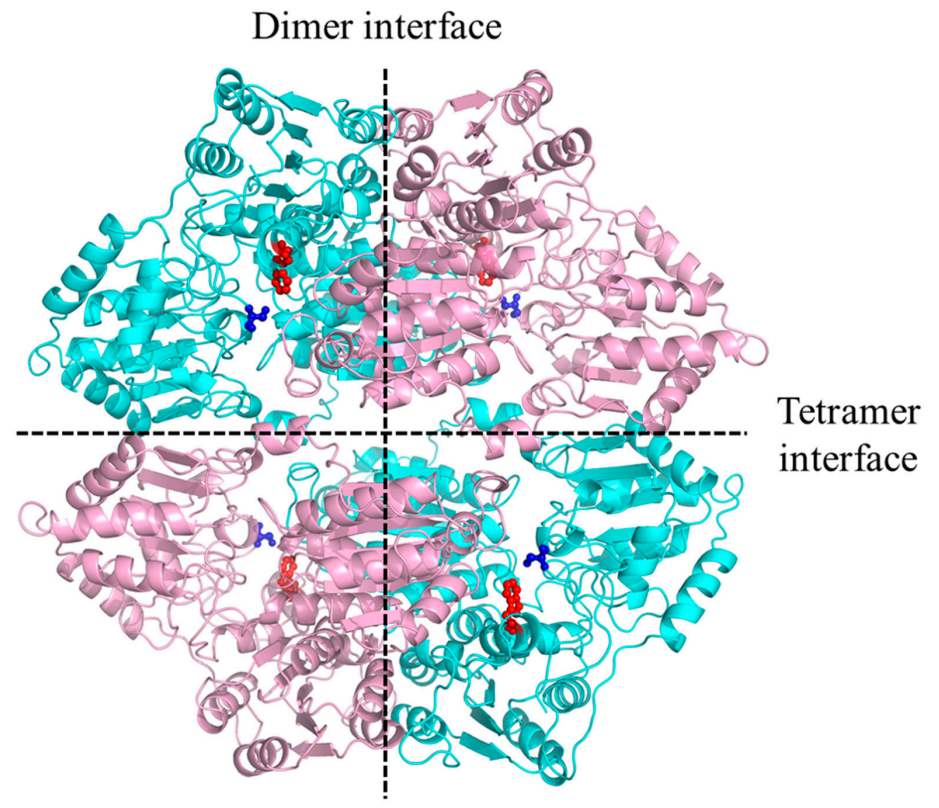

Figure 9. The W548 location in the AHAS-WT tetramer. The interfaces were labeled by dash Lines. The backbone of the monomer was colored as pink and cyan, respectively. W548 was shown as a red stick-ball model, S627 was shown as a blue stick-ball model. 


\subsection{Mechanism of Herbicide Tolerance for the AHAS- $\triangle W 548$}

Herbicide tolerance was generated when some mutations weakened the binding between AHAS and an herbicide [14]. A SU/PYB herbicide was bound to the W548 with a $\pi-\pi$ interaction $[27,28]$. When the W548 was replaced with a non-aromatic residue, the $\pi-\pi$ interaction disappeared and herbicide tolerance was generated $[29,30]$. Herbicide tolerance also occurred when the W548 was replaced with other aromatic residues [31]. The benzene ring in tyrosine or phenylalanine changed the orientation and dihedral angle, reducing the $\pi-\pi$ interaction. The AHAS channel varied its conformation to the herbicide binding [28]. The loss of the $\pi-\pi$ interaction of the AHAS- $\Delta$ W 548 was supposed to change the protein's conformation. This variation might shift the herbicide position and allow substrates access to the active center. The BS induced the cleavage of a thiazolium ring, which reduced the cofactor content and binding affinity [15]. It was the largest molecule in all tested herbicides and occupied more space in the channel. This occupation could cause the reduction of the reaction velocity of the AHAS- $\triangle$ W548. The binding between IT and AHAS caused a negative effect on the active site [28]. This effect might decrease binding affinity and the passing speed of substrates.

\subsection{Development of HT Genes Using Residue Deletion}

Besides the W548 mutations, several mutations in AHAS conferred tolerance to herbicides [14]. The S627N mutation conferred tolerance to IMI [23]. The AHAS mutations, such as K256F, M351C, $\mathrm{H} 352 \mathrm{Q}$, and F578D, led to tolerance to SU, IMI, and triazolopyrimidine [16]. Other endogenous enzymes were targeted by the herbicides which action modes were different from AHAS-inhibiting herbicides. Those enzymes included photosystem two complex, ACCase, 5-enolpyruvylshikimate-3-phosphate synthase (EPSPS), tubulin, and protoporphyrinogen IX oxidase [32]. Amino acid substitution in those enzymes led to herbicide tolerance. Those mutations could be candidates of single amino acid deletion. The deletion probably conferred herbicide tolerance to an enzyme. The W548L/S627I double mutation performed high BS tolerance of rice AHAS [33]. Moreover, simulated structures and herbicide docking could check the possibility of herbicide tolerance in modified enzymes. The deletion of two or more residues would be engineered to pursue extra herbicide tolerance in the further research.

\subsection{The Effects of the Ahas- $\Delta W 548$ Gene on the Line9}

Transgene position affected parent phenotypes when T-DNA inserted into a certain functional gene [34]. No change of the phenotype demonstrated that the T-DNA position in the Line9 genome did not produce negative effects. Overexpression of some endogenous gene reduced rice yields [35]. The similar traits between Line9 and its parent suggested that AHAS- $\Delta$ W548 overexpression did not reduce rice yield in this line. The Line9 height with FC treatment suggested that the residual activity of the AHAS- $\triangle$ W548 is sufficient to maintain rice normal growth. A P450 monooxygenase in wild-type rice could degrade the BS to some degree [36], thus the plants with the BS treatment were higher than those with the IT treatment. Weedy rice had tolerance to the herbicides which were detoxified by non-biotech rice [2]. It was eliminated by the herbicides which killed non-biotech rice. Death of Xiushui134 implied that the tested herbicides could eliminate weedy rice. The SM treatment in the fields indicated that this herbicide could be used to control weeds and produce accepted yields. A substitution mutant enhanced BCAA contents to be two-fold in the seeds [37]. The AHAS- $\triangle W 548$ overexpression in Line9 displayed more fold than the substitution mutant. The BCAA compounds were of bitter taste [38]. However, the bitter thresholds of the valine, leucine, and isoleucine were $3.4 \mathrm{mM}, 11 \mathrm{mM}$, and $10 \mathrm{mM}$, separately. A bitter amino acid enhanced the umami taste of foods at subthreshold concentrations [39]. The BACC contents of Line9 seeds were lower than their bitter threshold. It is a possibility that those BACC could enhance the umami taste of the rice. 


\subsection{Novel Herbicide-Tolerant Biotech Crops}

Novel HT crops are desired in the market [1]. The EPSPS has been utilized as the target of glyphosate for dozens of years [40]. Weeds evolved glyphosate tolerance in soybean fields. Transgenic soybean expressing an IMI-tolerant AHAS was developed to control those weeds [41]. Current HT rice had high tolerance to IMI but not to SU [12]. The weedy rice evolving IMI tolerance could be controlled by the SU-tolerant Line9. Recently, precise gene modification efficiently generated HT crops. The HT rice was engineered through introducing mutations into endogenous ahas gene using the transcription activator-like effector nucleases (TALEN) [33] and the clustered regularly interspaced short palindromic repeats (CRISPR) mediated mutagenesis [42]. CRISPR technology introduced a mutation into endogenous EPSPS gene and produced glyphosate-tolerant rice [43]. Crops could develop herbicide tolerance by deleting single amino acid from an endogenous gene. In the future, the W548 codon would be removed from rice endogenous ahas gene to generate herbicide tolerance.

\section{Materials and Methods}

\subsection{Structural Simulation of Rice AHAS-Herbicide Complexes}

Structures of rice AHAS were predicted using the online server SWISS-MODEL [44]. The AHAS sequence of japonica rice was found in the National Center for Biotechnology Information (NCBI, GenBank ID: BAB20812). Although no structure of rice AHAS has been determined, crystallographic structures of Arabidopsis AHAS are deposited in the Protein Data Bank (PDB). Structures of rice AHAS are simulated using homologous complexes of Arabidopsis. Herbicide molecules were retrieved from the PubChem database (Table S2). They were docked into the corresponding structures using the Maestro (v10.2) software bundle (Schrödinger L.L.C., New York, NY). The Glide program was used to predict the binding conformation in herbicide-AHAS complexes [45].

\subsection{Purification of the AHAS Proteins}

General experiments were similar as previously described with minor modifications [23]. The ahas sequence of japonica rice was found in the NCBI (GenBank ID: AB049822). The ahas-WT was amplified from japonica rice (Xiushui134) using the PCR. The primers were AHAS-F and AHAS-R (all sequences of primers were synthesized by Shanghai Sangon Biotech and were listed in Table S3). Site-directed mutagenesis kit (Qiagen, Lane Valencia, CA, USA) was used to delete the W548 codon and generate the ahas- $\Delta W 548$. The primers were AHAS-W548F and AHAS-W548R. The sequences of ahas-WT and ahas- $\Delta W 548$ were verified through DNA sequencing and the Vector NTI software (ThermoFisher Scientific, Waltham, MA, USA). Signal peptides of the N-terminal 59 amino acids were removed by the PCR to express the mature AHAS in Escherichia coli [46]. The primers were AHAS-BamHI-F and AHAS-EcoRI-R. The ahas genes were cloned into pGEX4T2 (GE Healthcare, Pittsburgh, PA). The resultant plasmids were transformed into E. coli Rosetta (Novagen, Sacramento, CA, USA) cells for protein expression. When cell culture grew to the log phase, protein expression was induced with $1 \mathrm{mM}$ isopropyl $\beta$-D-1-thiogalactopyranoside (chemicals in this study were purchased from Sigma-Aldrich Corp., St. Louis, MO, USA) and incubated with shaking at $25^{\circ} \mathrm{C}$ for $6 \mathrm{~h}$. The AHAS protein fused with an N-terminal glutathione S-transferase (GST) tag was isolated using a glutathione agarose column. The fusion protein was cleaved by a Thrombin CleanCleave Kit (Sigma-Aldrich Corp.). The resultant mixture was passed through the same column again. Mature AHAS proteins were isolated in the flow-through fraction and were analyzed using sodium dodecyl sulfate-polyacrylamide gel electrophoresis (SDS-PAGE). Gel filtration chromatography was used to determine oligomeric states and examine the homogeneity of purified proteins [47]. A high-performance liquid chromatography system and an Ultrahydrogel 1000 SEC column (Waters Corp., Milford, Massachusetts) were used in the experiment. 


\subsection{Activities and Kinetic Assays of Rice AHAS in Vitro}

Activity and kinetic assays were conducted following a reported method [48]. An assay buffer contained $50 \mathrm{mM}$ phosphate buffer ( $\mathrm{pH} 7.5), 10 \mathrm{mM} \mathrm{MgCl}, 20 \mu \mathrm{M}$ flavin adenine dinucleotide, $1 \mathrm{mM}$ thiamine pyrophosphate, $40 \mathrm{mM}$ pyruvate, and $1 \mu \mathrm{M}$ purified AHAS. Herbicides were added into the reaction at specific concentrations. After incubation at $37^{\circ} \mathrm{C}$ for one hour, $\mathrm{H}_{2} \mathrm{SO}_{4}$ was added to a final concentration of $1 \%$ to stop the reaction. Produced acetolactate was decarboxylated to generate acetoin at $60{ }^{\circ} \mathrm{C}$ for $30 \mathrm{~min}$. The acetoin was incubated with $0.5 \%$ creatine and $5 \% \alpha$-naphthol at $60^{\circ} \mathrm{C}$ for $15 \mathrm{~min}$. The mixture changed color from yellow to red. Absorbance was detected at $525 \mathrm{~nm}$ $\left(A_{525} \mathrm{~nm}\right)$. The $A_{525} \mathrm{~nm}$ value $\left(A_{B k}\right)$ without the enzyme was considered $0 \%$. The $A_{525 \mathrm{~nm}}$ value $\left(A_{W T}\right)$ for AHAS-WT was recorded in the absence of an herbicide. The value $\left(A_{100}\right)$ of $A_{W T}$ minus $A_{B K}$ was considered $100 \%$. The $A_{525 n}$ value $\left(A_{S}\right)$ of a sample was recorded. The percentage of remaining AHAS activity $\left(\mathrm{R}_{\%}\right)$ was calculated by the Equation (1):

$$
\mathrm{R}_{\%}=\left(\mathrm{A}_{\mathrm{S}}-\mathrm{A}_{\mathrm{Bk}}\right) \times 100 / \mathrm{A}_{100}
$$

Continuous assays explored the effects of the W548 deletion on AHAS catalytic efficiencies. Kinetic values were determined by differing pyruvate concentrations. An herbicide was added at a concentration of $100 \mu \mathrm{M}$. The assay measured the reaction velocity $(v)$ at different the pyruvate concentration ([S]) with the fixed concentration of the AHAS dimers ([E]). The Michaelis-Menten constant $\left(K_{m}\right)$ and catalytic rate constant $\left(K_{c a t}\right)$ were obtained through the Equation (2):

$$
v=V_{\max } \times[S] /\left(K_{m}+[S]\right) \text { and } K_{c a t}=V_{\max } /[E]
$$

The catalytic efficiency was calculated by dividing $K_{c a t}$ by $K_{m}$. The activity or kinetic assay was conducted in triplicate.

\subsection{Development of Transgenic Rice}

The ahas- $\Delta W 548$ gene was used as a selection marker in the transformation procedure. A T-DNA cassette based on the vector pCAMBIA1300 (1300 for short, Cambia, Australia) was assembled to express the AHAS- $\triangle$ W548 in rice. The hygromycin-resistant gene was removed from the 1300 vector with XhoI. The digested sites were dephosphated with alkaline phosphatase. The modified vector was named 1300-XhoI-DP. The ahas- $\triangle W 548$ was amplified with the primers AHAS-XhoI-F and AHAS-XhoI-R. The PCR product was digested with XhoI and cloned into the 1300-XhoI-DP. The correct direction of the ahas- $\triangle W 548$ was confirmed with DNA sequencing. The resultant construct was named 1300-AHAS- $\triangle$ W548 and was transformed into an Agrobacterium tumefaciens stain (LBA4404, ThermoFisher Scientific). Xiushui134 calluses were used as a recipient. Rice transformation was conducted following a previous protoco 1 [49]. The selection agent was $1 \mathrm{mM} \mathrm{SM}$, applied in the process of tissue culture. Transgenic plants were scanned with the PCR in the T0 generation. The genomic DNA of Xiushui134 was used as a negative control. Plasmid DNA of the 1300-AHAS- $\Delta$ W548 was used as a positive control. The primers AHAS-1665F and AHAS-1717R were designed to distinguish the ahas- $\triangle W 548$ (50bp) fragment from ahas-WT (53bp). The PCR fragments were resolved on a $20 \%$ PAGE gel. Seeds were harvested from positive plants.

\subsection{Herbicide Tolerance and Agronomic Traits of Transgenic Lines}

The T1 plants were sprayed with $0.25 \mathrm{~g} / \mathrm{L} \mathrm{SM}$ at the seedling stage. Survival lines were considered HT rice. The relative expression of those plants was measured at the maturity stage by Quant Studio6 Real-time PCR system (ThermoFisher Scientific) [23]. Trizol solution was used to extract total RNA from rice leaf. M-MuLV First Strand cDNA Synthesis Kit (Shenggong Inc. Shanghai) was used to transcribe RNA to cDNA. Primers AHAS-341F/AHAS-500R and primers actin-F/actin-R were used to amplify the target and reference, separately. Level of ahas mRNA expression in the Xiushui134 was 
treated as 1.0. Expression were presented as the relative mRNA level. Every sample of a plant was analyzed in triplicate. Samples from five plants were detected for each line. Agronomic traits were observed in fields. The T1 seeds were harvested from the line for which the traits were similar to Xiushui134. The T2 plants were treated with $0.25 \mathrm{~g} / \mathrm{L} \mathrm{SM}, 0.17 \mathrm{~g} / \mathrm{L} \mathrm{RS}, 0.20 \mathrm{~g} / \mathrm{L} \mathrm{CM}, 0.09 \mathrm{~g} / \mathrm{L} \mathrm{FC}, 0.8 \mathrm{~g} / \mathrm{L}$ $\mathrm{BS}$ or $2.2 \mathrm{~g} / \mathrm{L}$ IT at the seedling stage in a greenhouse. In an herbicide treatment, four plants grew in a plate and ten plants were treated with an herbicide. Xiushui134 without the herbicide treatment was used as a positive control. Two weeks later, the value $(\mathrm{H})$ of the plant height was recorded. The height value $\left(\mathrm{H}_{100}\right)$ of positive control was considered $100 \%$. The percentage $\left(\mathrm{H}_{\%}\right)$ of the relative height was calculated by the Equation (3):

$$
\mathrm{H}_{\%}=\mathrm{H} \times 100 / \mathrm{H}_{100}
$$

Additionally, the T2 plants were characterized in weed-free fields. In one field, the transgenic line was treated with $0.25 \mathrm{~g} / \mathrm{L} \mathrm{SM}$ at the seedling stage. In other fields, the transgenic line and Xiushui134 were grown without the herbicide treatment [50]. Five plots of $1.0 \mathrm{~m}^{2}$ were chosen randomly for traits evaluation in one field. Every plot contained 30 plants. We measured the plant height and panicle numbers per plant at the maturity stage in fields. Panicles of an individual plant were collected to determine the seed-setting rate, grains per panicle and yield per plant in a laboratory. A QM3 rice analyzer system (Vibe, Bnei Brak, Israel) was used to measure 1000-grain weight, grain width, and grain length.

\subsection{Measurement of Total Protein and Free Amino Acids in Rice Seeds}

One kilogram of the Line9 seeds was weighted randomly from the seeds harvested from fields. They were ground into powder by a grinder (Dickey John, Auburn, IL). Total proteins were calculated from the nitrogen content: protein $\%=\mathrm{N} \% / 0.16$. The nitrogen content was measured with the Kjeldahl method [51]. The analysis was applied according to the manual of the Kjeltec 8400 instrument (FOSS, Hovedstaden, Danmark). To determinate the free amino acid content, the rice powder was added into $50 \%(v / v)$ methanol containing piperazine-1,4-bisethanesulfonic acid and methionine sulfone [37]. The mixture was centrifuged at 13,000 $\mathrm{g}$ for $10 \mathrm{~min}$, the supernatant passed through a $5 \mathrm{kDa}$ Amicon Ultra centrifugal filter unit (Merck, Darmstadt, Germany). The solution was loaded into an automatic amino acid analyzer (model L-8900; Hitachi, Tokyo, Japan) with cation-exchange chromatography. Amino acid standards were set up to calculate the contents. Each sample of the powder was repeated in triplicate. Three samples were analyzed in each experiment.

\subsection{Data Analysis}

The kinetic parameters of the AHAS- $\Delta$ W548 were compared with those of the AHAS-WT using the student's $t$-test [23]. The agronomic traits and free amino acid content were compared with those of Xiushui134 using the same test. The bioassay curves and plant height columns were generated by the Excel of Office 2016.

\section{Conclusions}

The Line9 plants expressing the AHAS- $\Delta$ W548 showed good agronomic traits with the herbicide treatment. Although transgenic rice was limited in laboratories by the Chinese government, the transgene-free CRISPR technology could directly modify a gene in a genome and produced crops without any transgene. The Line9 proved that the ahas- $\Delta W 548$ gene was a good candidate for endogenous modification to develop non-transgenic rice with herbicide tolerance.

Supplementary Materials: Supplementary materials can be found at http://www.mdpi.com/1422-0067/21/4/1265/s1.

Author Contributions: The experiments were conceived and designed by J.F., J.F. and C.W. conducted experiments. J.F. and W.W. wrote the manuscript. L.M. revised the paper. X.W., C.C. and J.Z. assisted with field experiments. Y.Q. and X.W. analyzed data. All authors have read the paper and have approved the final manuscript. 
Funding: The work was supported by the Shanghai Agriculture Applied Technology Development Program (Grant No. G2015060103), Natural Science Foundation of Shanghai (No.15ZR1436500), and SAAS Excellent Research Team (No. NKC2017A05).

Conflicts of Interest: The authors declare no conflict of interest.

\section{References}

1. ISAAA. Global status of commercialized biotech/GM crops in 2017: Biotech crop adoption surges as economic benefits accumulate in 22 years. ISAAA Brief 2017, 53, 104-106.

2. Chauhan, B.S. Strategies to manage weedy rice in Asia. Crop Prot. 2013, 48, 51-56. [CrossRef]

3. Owen, M.D.; Beckie, H.J.; Leeson, J.Y.; Norsworthy, J.K.; Steckel, L.E. Integrated pest management and weed management in the United States and Canada. Pest Manag. Sci. 2015, 71, 357-376. [CrossRef] [PubMed]

4. Wang, Z.; Rong, J.; Lu, B.R. Occurence and damage of weedy rice and its threats to rice production in China. Weed Sci. (China) 2015, 33, 1-9.

5. Kanapeckas, K.L.; Vigueira, C.C.; Ortiz, A.; Gettler, K.A.; Burgos, N.R.; Fischer, A.J.; Lawton-Rauh, A.L. Escape to ferality: The endoferal origin of weedy rice from crop rice through de-domestication. PLoS ONE 2016, 11. [CrossRef]

6. Islam, M.; Biswas, J.; Siyoung, L.; Alam, I.; Mooryong, H. Screening of rice varieties for direct seeding method. Aust. J. Crop Sci. 2014, 8, 536-542.

7. Liang, Y.; Guo, S.; Yin, L. Comparative study on morphological differences between weedy rice and cultivatec rice in Shanghai area. J. Shanghai Norm. Univ. (Nat. Sci.) 2014, 43, 87-97.

8. Bai, Y.L.; Gu, L.-L. The market and development of three types of pesticides on rice. Mod. Agrochem. 2017, 16, $1-7$.

9. Yasuor, H.; Osuna, M.D.; Ortiz, A.; Saldain, N.E.; Eckert, J.W.; Fischer, A.J. Mechanism of resistance to penoxsulam in late watergrass [Echinochloa phyllopogon (Stapf) Koss.]. J. Agric. Food Chem. 2009, 57, 3653-3660. [CrossRef]

10. Ruiz-Santaella, J.P.; Heredia, A.; Prado, R.D. Basis of selectivity of cyhalofop-butyl in Oryza sativa L. Planta 2006, 223, 191-199. [CrossRef]

11. Rashid, M.H.; Alam, M.M.; Rao, A.N.; Ladha, J.K. Comparative efficacy of pretilachlor and hand weeding in managing weeds and improving the productivity and net income of wet-seeded rice in Bangladesh. Field Crop. Res. 2012, 128, 17-26. [CrossRef]

12. Tan, S.; Evans, R.R.; Dahmer, M.L.; Singh, B.K.; Shaner, D.L. Imidazolinone-tolerant crops: History, current status and future. Pest Manag. Sci. 2005, 61, 246-257. [CrossRef] [PubMed]

13. Gutteridge, S.; Thompson, M.E.; Ort, O.; Shaner, D.L.; Stidham, M.; Singh, B.; Tan, S.; Johnson, T.C.; Mann, R.K.; Schmitzer, P.R.; et al. Acetohydroxyacid synthase inhibitors (AHAS/ALS). Mod. Crop Prot. Compd. Second Ed. 2012. [CrossRef]

14. Duggleby, R.G.; McCourt, J.A.; Guddat, L.W. Structure and mechanism of inhibition of plant acetohydroxyacid synthase. Plant Physiol. Biochem. 2008, 46, 309-324. [CrossRef]

15. Garcia, M.D.; Nouwens, A.; Lonhienne, T.G.; Guddat, L.W. Comprehensive understanding of acetohydroxyacid synthase inhibition by different herbicide families. Proc. Natl. Acad. Sci. USA 2017, 114, 1091-1100. [CrossRef]

16. Yu, Q.; Powles, S.B. Resistance to AHAS inhibitor herbicides: Current understanding. Pest Manag. Sci. 2014, 70, 1340-1350. [CrossRef]

17. Guttieri, M.J.; Eberlein, C.V.; Mallory-Smith, C.A.; Hoffman, D.L. DNA-sequence variation in domain a of the acetolactate synthase genes of herbicide-resistant and herbicide-susceptible weed biotypes. Weed Sci. 1992, 40, 670-676. [CrossRef]

18. MallorySmith, C.A.; Thill, D.C.; Dial, M.J. Identification of sulfonylurea herbicide-resistant prickly lettuce (Lactuca serriola). Weed Technol. 1990, 4, 163-168. [CrossRef]

19. Liu, Y.; Li, Y.; Wang, X. Acetohydroxyacid synthases: Evolution, structure, and function. Appl. Microbiol. Biotechnol. 2016, 100, 8633-8649. [CrossRef]

20. Shivraina, V.K.; Burgosa, N.R.; Andersb, M.M.; Rajgurua, S.N.; Moorea, J.; Sales, M.A. Gene flow between Clearfield ${ }^{\mathrm{TM}}$ rice and red rice. Crop Prot. 2007, 26, 349-356. [CrossRef] 
21. Jones, J.M.; Dionne, L.; Dell'Orco, J.; Parent, R.; Krueger, J.N.; Cheng, X.; Dib-Hajj, S.D.; Bunton-Stasyshyn, R.K.; Sharkey, L.M.; Dowling, J.J.; et al. Single amino acid deletion in transmembrane segment D4S6 of sodium channel Scn8a (Nav1.6) in a mouse mutant with a chronic movement disorder. Neurobiol. Dis. 2016, 89, 36-45. [CrossRef] [PubMed]

22. Pagadala, N.S.; Syed, K.; Tuszynski, J. Software for molecular docking: A review. Biophys. Rev. 2017, 9, 91-102. [CrossRef] [PubMed]

23. Piao, Z.; Wang, W.; Wei, Y.; Zonta, F.; Wan, C.; Bai, J.; Wu, S.; Wang, X.; Fang, J. Characterization of an acetohydroxy acid synthase mutant conferring tolerance to imidazolinone herbicides in rice (Oryza sativa). Planta 2018, 247, 693-703. [CrossRef] [PubMed]

24. Pang, S.S.; Guddat, L.W.; Duggleby, R.G. Crystallization of Arabidopsis thaliana acetohydroxyacid synthase in complex with the sulfonylurea herbicide chlorimuron ethyl. Acta Crystallogr. D Biol. Crystallogr. 2004, 60, 153-155. [CrossRef]

25. Kawai, K.; Kaku, K.; Izawa, N.; Shimizu, T.; Fukuda, A.; Tanaka, Y. A novel mutant acetolactase synthase gene from rice cells which confers resistance to ALS-inhibiting herbicides. J. Pest. Sci. 2007, 32, 89-98. [CrossRef]

26. Chang, A.K.; Duggleby, R.G. Herbicide-resistant forms of Arabidopsis thaliana acetohydroxyacid synthase: Characterization of the catalytic properties and sensitivity to inhibitors of four defined mutants. Biochem. J. 1998, 333, 765-777. [CrossRef]

27. Lonhienne, T.; Garcia, M.D.; Pierens, G.; Mobli, M.; Nouwens, A.; Guddat, L.W. Structural insights into the mechanism of inhibition of AHAS by herbicides. Proc. Natl. Acad. Sci. USA 2018, 115, 1945-1954. [CrossRef]

28. Garcia, M.D.; Wang, J.G.; Lonhienne, T.; Guddat, L.W. Crystal structure of plant acetohydroxyacid synthase, the target for several commercial herbicides. FEBS J. 2017, 284, 2037-2051. [CrossRef]

29. Falco, S.C.; McDevitt, R.E.; Chui, C.F.; Hartnett, M.E.; Knowlton, S.; Mauvais, C.J.; Smith, J.K.; Mazur, B.J. Engineering herbicide-resistant acetolactate synthase. Dev. Ind. Microbiol. 1989, 30, 187-194.

30. Duggleby, R.G.; Pang, S.S.; Yu, H.; Guddat, L.W. Systematic characterization of mutations in yeast acetohydroxyacid synthase. Interpretation of herbicide-resistance data. Eur. J. Biochem. 2003, 270, 2895-2904. [CrossRef]

31. Ibdah, M.; Bar-Ilan, A.; Livnah, O.; Schloss, J.V.; Barak, Z.; Chipman, D.M. Homology modeling of the structure of bacterial acetohydroxy acid synthase and examination of the active site by site-directed mutagenesis. Biochemistry 1996, 35, 16282-16291. [CrossRef] [PubMed]

32. Powles, S.B.; Yu, Q. Evolution in action: Plants resistant to herbicides. Annu. Rev. Plant Biol. 2010, 61, 317-347. [CrossRef] [PubMed]

33. Li, T.; Liu, B.; Chen, C.Y.; Yang, B. TALEN-mediated homologous recombination produces site-directed DNA base change and herbicide-resistant Rice. J. Genet. Genom. 2016, 43, 291-305. [CrossRef]

34. Feldmann, K.A.; Marks, M.D.; Christianson, M.L.; Quatrano, R.S. A dwarf mutant of Arabidopsis generated by T-DNA insertion mutagenesis. Science 1989, 243, 1351-1354. [CrossRef]

35. Liu, M.; Shi, Z.; Zhang, X.; Wang, M.; Zhang, L.; Zheng, K.; Liu, J.; Hu, X.; Di, C.; Qian, Q.; et al. Inducible overexpression of ideal plant Architecture1 improves both yield and disease resistance in rice. Nat. Plants 2019, 5, 389-400. [CrossRef]

36. Saika, H.; Horita, J.; Taguchi-Shiobara, F.; Nonaka, S.; Nishizawa-Yokoi, A.; Iwakami, S.; Hori, K.; Matsumoto, T.; Tanaka, T.; Itoh, T.; et al. A novel rice cytochrome P450 gene, CYP72A31, confers tolerance to acetolactate synthase-inhibiting herbicides in rice and Arabidopsis. Plant Physiol. 2014, 166, 1232-1240. [CrossRef]

37. Endo, M.; Shimizu, T.; Fujimori, T.; Yanagisawa, S.; Toki, S. Herbicide-resistant mutations in acetolactate synthase can reduce feedback inhibition and lead to accumulation of branched-chain amino acids. Food Nutr. Sci. 2013, 4, 522-528. [CrossRef]

38. Zhao, C.J.; Schieber, A.; Ganzle, M.G. Formation of taste-active amino acids, amino acid derivatives and peptides in food fermentations-a review. Food Res. Int. 2016, 89, 39-47. [CrossRef]

39. Lioe, H.N.; Apriyantono, A.; Takara, K.; Wada, K.; Yasuda, M. Umami taste enhancement of MSG/NaCl mixtures by subthreshold L-a-Aromatic amino acids. J. Food Sci. 2005, 70, 401-405. [CrossRef]

40. Funke, T.; Han, H.; Healy-Fried, M.L.; Fischer, M.; Schonbrunn, E. Molecular basis for the herbicide resistance of Roundup Ready crops. Proc. Natl. Acad. Sci. USA 2006, 103, 13010-13015. [CrossRef] 
41. EFSA. Scientific opinion on application (EFSA-GMO-NL-2009-64) for the placing on the market of herbicide-tolerant genetically modified soybean BPS-CV127-9 for food and feed uses, import and processing under regulation (EC) No 1829/2003 from BASF plant science. EFSA J. 2014, 12, 3505.

42. Sun, Y.; Zhang, X.; Wu, C.; He, Y.; Ma, Y.; Hou, H.; Guo, X.; Du, W.; Zhao, Y.; Xia, L. Engineering herbicide-resistant rice plants through CRISPR/Cas9-mediated homologous recombination of acetolactate synthase. Mol. Plant 2016, 9, 628-631. [CrossRef]

43. Li, J.; Meng, X.; Zong, Y.; Chen, K.; Zhang, H.; Liu, J.; Li, J.; Gao, C. Gene replacements and insertions in rice by intron targeting using CRISPR-Cas9. Nat. Plants 2016, 2. [CrossRef]

44. Biasini, M.; Bienert, S.; Waterhouse, A.; Arnold, K.; Studer, G.; Schmidt, T.; Kiefer, F.; Gallo Cassarino, T.; Bertoni, M.; Bordoli, L.; et al. SWISS-MODEL: Modelling protein tertiary and quaternary structure using evolutionary information. Nucleic Acids Res. 2014, 42, 252-258. [CrossRef] [PubMed]

45. Friesner, R.A.; Banks, J.L.; Murphy, R.B.; Halgren, T.A.; Klicic, J.J.; Mainz, D.T.; Repasky, M.P.; Knoll, E.H.; Shelley, M.; Perry, J.K.; et al. Glide: A new approach for rapid, accurate docking and scoring. J. Med. Chem. 2004, 47, 1739-1749. [CrossRef] [PubMed]

46. Chang, A.K.; Duggleby, R.G. Expression, purification and characterization of Arabidopsis thaliana acetohydroxyacid synthase. Biochem. J. 1997, 327, 161-169. [CrossRef] [PubMed]

47. Robards, K.; Haddad, P.R.; Jackson, P.E. High-performance liquid chromatography-separations. Princ. Pract. Mod. Chromatogr. Methods 2004, 6, 305-380.

48. Yoon, T.Y.; Chung, S.M.; Chang, S.I.; Yoon, M.Y.; Hahn, T.R.; Choi, J.D. Roles of lysine 219 and 255 residues in tobacco acetolactate synthase. Biochem. Biophys. Res. Commun. 2002, 293, 433-439. [CrossRef]

49. Hiei, Y.; Ohta, S.; Komari, T.; Kumashiro, T. Efficient transformation of rice (Oryza sativa L.) mediated by Agrobacterium and sequence analysis of the boundaries of the T-DNA. Plant J. 1994, 6, 271-282. [CrossRef]

50. Yang, Y.Y.; Mei, F.; Zhang, W.; Shen, Z.; Fang, J. Creation of Bt rice expressing a fusion protein of Cry1Ac and Cry1I-like using a green tissue-specific promoter. J. Econ. Entomol. 2014, 107, 1674-1679. [CrossRef]

51. Jiang, B.; Tsao, R.; Li, Y.; Miao, M. Food safety: Food analysis technologies/techniques. Encycl. Agric. Food Syst. 2014, 273-288. [CrossRef]

(C) 2020 by the authors. Licensee MDPI, Basel, Switzerland. This article is an open access article distributed under the terms and conditions of the Creative Commons Attribution (CC BY) license (http://creativecommons.org/licenses/by/4.0/). 